\title{
Perinatal mortality in breech presentations as compared to vertex presentations in singleton pregnancies: an analysis based upon 57819 computer-registered pregnancies in The Netherlands
}

\author{
M.F. Schutte ${ }^{1}$, O.J.S. van Hemel ${ }^{2}$, C. van de Berg ${ }^{3}$ and A. van de Pol ${ }^{3}$ \\ ${ }^{\prime}$ Onze Lieve Vrouwe Gasthuis, Amsterdam, 'St. Hippolytus ziekenhuis, Delft, ${ }^{3}$ Landelijke Verloskundige \\ Registratie (LVR), Utrecht, The Netherlands
}

Accepted for publication 21 January 1985

SCHUTTE, M.F., VAN HEMEL, O.J.S., VAN DE BERG, C and VAN DE POI, A (1985): Perinatal mortality in breech presentations as compared to vertex presentations in singleton pregnancies: an analysis based upon 57819 computer-registered pregnancies in the Netherlands. Europ. J. Obstet. Gynec. reprod. Biol., 19, 391-400.

In 1982, nationwide registration of obstetric data was instituted in The Netherlands with about $70 \%$ of all Dutch hospitals participating. The resultant data from 57819 singleton pregnancies in vertex or breech presentation at delivery was studied. The vertex and breech groups were compared.

The proportion of breech presentations relative to vertex presentations was greater in low gestational age infants and those of low birthweight. After correction for gestational age and birthweight, the perinatal mortality was higher in the breech groups than in the vertex groups.

Congenital malformations occurred more frequently in the breech group but, even after exclusion of infants with congenital malformations, perinatal mortality remained higher in the breech group at any gestational age. Caesarean section was more frequently performed in the breech group than in the vertex group but did not appear to improve the outcome of breech presentation.

It is possible that breech presentation is not coincidental but is a consequence of poor fetal quality, in which case medical intervention is unlikely to reduce the perinatal mortality associated with breech presentation to the level associated with vertex presentation.

breech presentation; vertex presentation; computer registration

\section{Introduction}

The management of breech presentation is an issue debated worldwide. Although there is general agreement about the relatively poor outcome of breech presentation

Address for correspondence: Dr. M.F. Schutte, Anna Paviljoen Onze Lieve Vrouwe Gasthuis, Eerste Oosterparkstraat 179, 1091 HA Amsterdam, The Netherlands. 
compared to vertex, there is still uncertainty as to its optimum management. In an endeavour to improve perinatal outcome for the breech infant, primary caesarean section has been advocated for all breech presentations (Wright, 1959), and in preterm or low-birthweight infants the risk of death due to head entrapment and cord prolapse is considered to be a reason for routine caesarean section (van Eyk and Huisjes, 1983). However, breech delivery by caesarean section requires considerable manipulation of the fetus, often resulting in injury similar to that seen at vaginal delivery (Grimovsky and Paul, 1982); an increased caesarean section rate for term breech delivery does not seem to reduce the unfavourable outcome significantly (Green et al., 1982), and Effer et al. (1983) found that neonatal mortality was not definitely different in infants delivered vaginally. Also De Jong and Stolte (1981) found no hazardous influence on the integrity of the central nervous system in vaginal delivery at term breech presentation compared to vertex.

Probably an expectant approach with a liberal policy towards the use of caesarean section is the management of choice while the present uncertainty about breech presentation and delivery remains unresolved.

With the introduction of nationwide registration of obstetric data in The Netherlands, the results of 128 clinics representing about $70 \%$ of all hospital confinements in the country have become available for evaluation.

The aim of this study was to show how computer analysis of the data from such a large number of patients may be used and to demonstrate thereby the significance of perinatal mortality in the problem of the management of breech presentation.

\section{Materials and methods}

On the basis of former work (van Hemel, 1972) the obstetric data from 128 clinics in The Netherlands has, since 1982, been registered in a central computer under a project known as LVR (Landelijke Verloskundige Registratie) prepared by a committee whose members have visited and instructed all participating clinics. A special coded form is completed by the obstetrician immediately after delivery and sent to the LVR, where it is fed into the computer. The computer subjects the data to a plausibility programme which seeks impossible and improbable combinations in the codings on the form and prints the recorded information in the form of a patientdischarge letter which is returned to the obstetrician along with any remark from the plausibility programme. A correction form is sent to the LVR by the obstetrician with appropriate amendments to the delivery data and information relating to the first week postpartum. All participating clinics receive monthly and yearly reviews of their own results and annual reviews of results from all clinics.

For this study data concerning infants of singleton pregnancies coded to be in either vertex or breech presentation immediately prior to abdominal or vaginal delivery were used. The data relate only to deliveries in hospital, as those occurring at home were not included in the project during the period of study. From this data the interrelationships between gestational age, birthweight, perinatal mortality, method of delivery, congenital malformations and presentation were analysed.

Congenital malformations were considered to be present only by virtue of their being recorded on the coded form, irrespective of their severity, so that the numbers 
are probably biased towards major deformations due to under-reporting of minor and trivial malformations.

Statistical analyses were made by trend-test, test for trends in odds ratio (Breslow, 1980) and chi-squared test.

\section{Results}

Incidence of vertex and breech presentation (Tables I and II)

Eight percent of all singleton infants showed a breech presentation at delivery. In the group of infants with either a low gestational age (16-27 wk) or a very low brithweight (under $1000 \mathrm{~g}$ ) the incidence of breech presentation almost equalled that of vertex presentation. Infants born at term or with a normal birthweight (from 2500 g) were delivered almost 13-times as frequently in vertex presentation as in breech presentation. The difference is statistically significant $(P<0.001)$.

\section{Perinatal mortality}

Perinatal mortality was almost 6-times higher in the breech group than in the vertex group $(9.7 \%$ versus $1.7 \%$, Tables III and IV). Although perinatal mortality

\section{TABLE I}

Incidence of vertex and breech presentations in singleton pregnancies according to gestational age

\begin{tabular}{lcccc}
\hline Gestational & \multicolumn{2}{c}{ Vertex presentation } & & \multicolumn{2}{c}{ Breech presentation } \\
\cline { 2 - 3 } age (wk) & No. & $(\%)$ & & No. \\
\hline $16 \cdot 27$ & 314 & $(57)$ & 236 & $(43)$ \\
$28-32$ & 602 & $(75)$ & 199 & $(25)$ \\
$33-36$ & 3127 & $(89)$ & 356 & $(11)$ \\
$\geqslant 37$ & 43234 & $(93)$ & 3520 & $(7)$ \\
Unknown & 3914 & $(93)$ & 317 & $(7)$ \\
Total & 53191 & $(92)$ & 4628 & $(8)$ \\
\hline
\end{tabular}

TABLE II

Incidence of vertex and breech presentations in singleton pregnancies according to birthweight

\begin{tabular}{lcccc}
\hline $\begin{array}{l}\text { Birthweight } \\
(\mathrm{g})\end{array}$ & \multicolumn{2}{l}{ Vertex presentation } & & \multicolumn{2}{c}{ Breech presentation } \\
\cline { 2 - 5 } \cline { 4 - 5 } & No. & $(\%)$ & & No. \\
\hline$<1000$ & 371 & $(54)$ & 319 & $(46)$ \\
$1000-1499$ & 419 & $(75)$ & 140 & $(25)$ \\
$1500-1999$ & 842 & $(84)$ & 157 & $(16)$ \\
$2000-2499$ & 2537 & $(88)$ & 348 & $(12)$ \\
$2500-3499$ & 43290 & $(93)$ & 3404 & $(7)$ \\
$3500-4499$ & 4734 & $(96)$ & 202 & $(4)$ \\
$\geqslant 4500$ & 857 & $(97)$ & 28 & $(3)$ \\
Unknown & 132 & $(81)$ & 31 & $(9)$ \\
Total & 53191 & $(92)$ & 4628 & $(8)$ \\
\hline
\end{tabular}




\section{TABLE III}

Perinatal death in the vertex and breech groups according to gestational age

Percentages are calculated from the data in Table I.

\begin{tabular}{|c|c|c|c|c|}
\hline \multirow{3}{*}{$\begin{array}{l}\text { Gestational } \\
\text { age (wk) }\end{array}$} & \multicolumn{4}{|c|}{ Perinatal death } \\
\hline & \multicolumn{2}{|c|}{ Vertex presentation } & \multicolumn{2}{|c|}{ Breech presentation } \\
\hline & No. & (\%) & No. & $(\%)$ \\
\hline $16-27$ & 236 & $(75.2)$ & 217 & $(92.0)$ \\
\hline $28-32$ & 149 & (24.8) & 94 & $(47.2)$ \\
\hline $33-36$ & 150 & $(4.8)$ & 42 & (11.8) \\
\hline$\geqslant 37$ & 256 & $(0.6)$ & 51 & (1.4) \\
\hline Unknown & 98 & $(2.5)$ & 43 & (11.7) \\
\hline Total & 889 & (1.7) & 447 & $(9.7)$ \\
\hline
\end{tabular}

TABLE IV

Perinatal death in the vertex and breech groups according to birthweight

Percentages are calculated from the data in Table II

\begin{tabular}{lrrrrr}
\hline \multirow{2}{*}{$\begin{array}{l}\text { Birthweight } \\
\text { g) }\end{array}$} & \multicolumn{2}{l}{ Perinatal death } & & \multicolumn{2}{l}{ Breech presentation } \\
\cline { 2 - 3 } \cline { 5 - 6 } & \multicolumn{2}{l}{ Vertex presentation } & & No. & $(\%)$ \\
\cline { 2 - 4 } & No. & $(82.7)$ & 287 & $(90.0)$ \\
\hline$<1000$ & 307 & $(26.5)$ & 60 & $(42.9)$ \\
$1000-1499$ & 111 & $(11.5)$ & 28 & $(17.8)$ \\
$1500-1999$ & 97 & $(4.0)$ & 24 & $(6.9)$ \\
$2000-2499$ & 102 & $(0.5)$ & 35 & $(1.0)$ \\
$2500-3999$ & 231 & $(0.3)$ & 1 & $(0.5)$ \\
$4000-4499$ & 12 & $(0.5)$ & 0 & $(0)$ \\
$\geqslant 4500$ & 4 & $(18.9)$ & 12 & $(40.0)$ \\
Unknown & 25 & $(1.7)$ & 447 & $(9.7)$ \\
Total & 889 & & &
\end{tabular}

\section{TABLE V}

Stillbirth in the vertex and breech groups

Stillbirth = antepartum and intrapartum death; percentages calculated from the data in Table I.

\begin{tabular}{|c|c|c|c|c|}
\hline \multirow{3}{*}{$\begin{array}{l}\text { Gestational } \\
\text { age (wk) }\end{array}$} & \multicolumn{4}{|c|}{ Stillbirth } \\
\hline & \multicolumn{2}{|c|}{ Vertex presentation } & \multicolumn{2}{|c|}{ Breech presentation } \\
\hline & No. & (若) & $\overline{\text { No. }}$ & (\%) \\
\hline $28-32$ & 108 & (18) & 68 & (34) \\
\hline $33-36$ & 113 & (4) & 29 & (8) \\
\hline$\geqslant 37$ & 186 & $(0.4)$ & 24 & $(0.7)$ \\
\hline
\end{tabular}




\section{TABLE VI}

Neonatal death in the vertex and breech groups

Neonatal death $=$ death within 7 days after birth; percentages calculated from the data in Table I.

\begin{tabular}{lllll}
\hline $\begin{array}{llll}\text { Gestational } \\
\text { age (wk) }\end{array}$ & \multicolumn{2}{l}{ Neonatal death } & \multicolumn{2}{l}{ Breech presentation } \\
\cline { 2 - 5 } & \multicolumn{2}{l}{ Vertex presentation } & & No. \\
\cline { 2 - 4 } & No. & $(\%)$ & 26 & $(19.8)$ \\
\hline $28-32$ & 41 & $(8.3)$ & 13 & $(4.0)$ \\
$33-36$ & 37 & $(1.2)$ & 27 & $(0.7)$ \\
\hline 37 & 70 & $(0.15)$ & & \\
\hline
\end{tabular}

decreases to the same extent in the breech and vertex groups with either increasing gestational age or increasing birthweight, in pregnancies with comparable gestational age or birthweight perinatal mortality was always higher in the breech group than in the vertex group $(P<0.005)$.

The incidence of stillbirth and neonatal death at various gestational ages is given in Tables V and VI. The incidence of stillbirth decreases by the same proportion in both the breech and vertex groups with increasing gestational age.

However, at all gestational ages the incidence of stillbirth was higher in the breech group than in the vertex group $(P<0.05)$.

Neonatal mortality in the first week after delivery decreases with increasing gestational age in both groups; in the vertex group it decreases more than in the breech group $(P<0.01)$ and is lower than in the breech group at any gestational age $(P<0.01)$.

\section{Caesarean section}

Caesarean section was more frequently performed in the breech group than in the vertex group $(26.5 \%$ versus $6.8 \%$, Table VII) irrespective of gestational age ( $P<$ 0.001 ). In the vertex groups the incidence of caesarean section was highest at a

\section{TABLE VII}

Perinatal death of infants delivered by caesarean section according to presentation at delivery

\begin{tabular}{|c|c|c|c|c|c|c|}
\hline \multirow{3}{*}{$\begin{array}{l}\text { Gestational } \\
\text { age (wk) }\end{array}$} & \multicolumn{3}{|c|}{ Vertex presentation } & \multicolumn{3}{|c|}{ Breech presentation } \\
\hline & \multirow[t]{2}{*}{ Total } & \multicolumn{2}{|c|}{ Perinat. death } & \multirow[t]{2}{*}{ Total } & \multicolumn{2}{|c|}{ Perinat. death } \\
\hline & & No. & $(\%)$ & & No. & (\%) \\
\hline $16-27$ & 3 & 0 & $(0)$ & 6 & 2 & (33) \\
\hline $28-32$ & 119 & 14 & $(11.8)$ & 61 & 12 & $(19.7)$ \\
\hline $33-36$ & 426 & 11 & (2.6) & 112 & 6 & $(5.4)$ \\
\hline$\geqslant 37$ & 2841 & 18 & $(0.6)$ & 967 & 10 & $(1.0)$ \\
\hline Unknown & 235 & $y$ & $(3.8)$ & 81 & 2 & (2.5) \\
\hline Total & 3624 & $52^{\mathrm{a}}$ & (1.4) & 1227 & $32^{b}$ & $(2.6)$ \\
\hline
\end{tabular}

\footnotetext{
a Stillborn: 18 infants.
}

b Stillborn: 5 infants. 


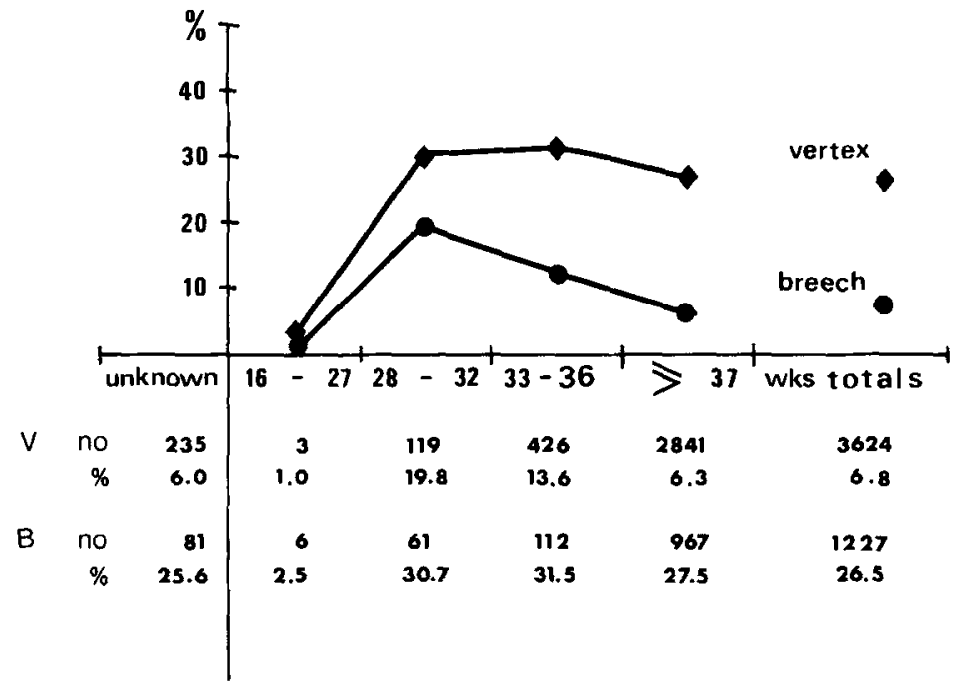

Fig. 1. The incidence of caesarean section in vertex (V) and breech (B) presentation according to gestational age in 57819 singleton pregnancies.

gestational age of 28-32 wk and declined thereafter (Fig. 1), while in the breech group the incidence did not decrease with increasing gestational age and the difference between the trends was significant $(P<0.001)$. Such a difference was not found in the case of infants with a birthweight of less than $1500 \mathrm{~g}$ (Fig. 2).

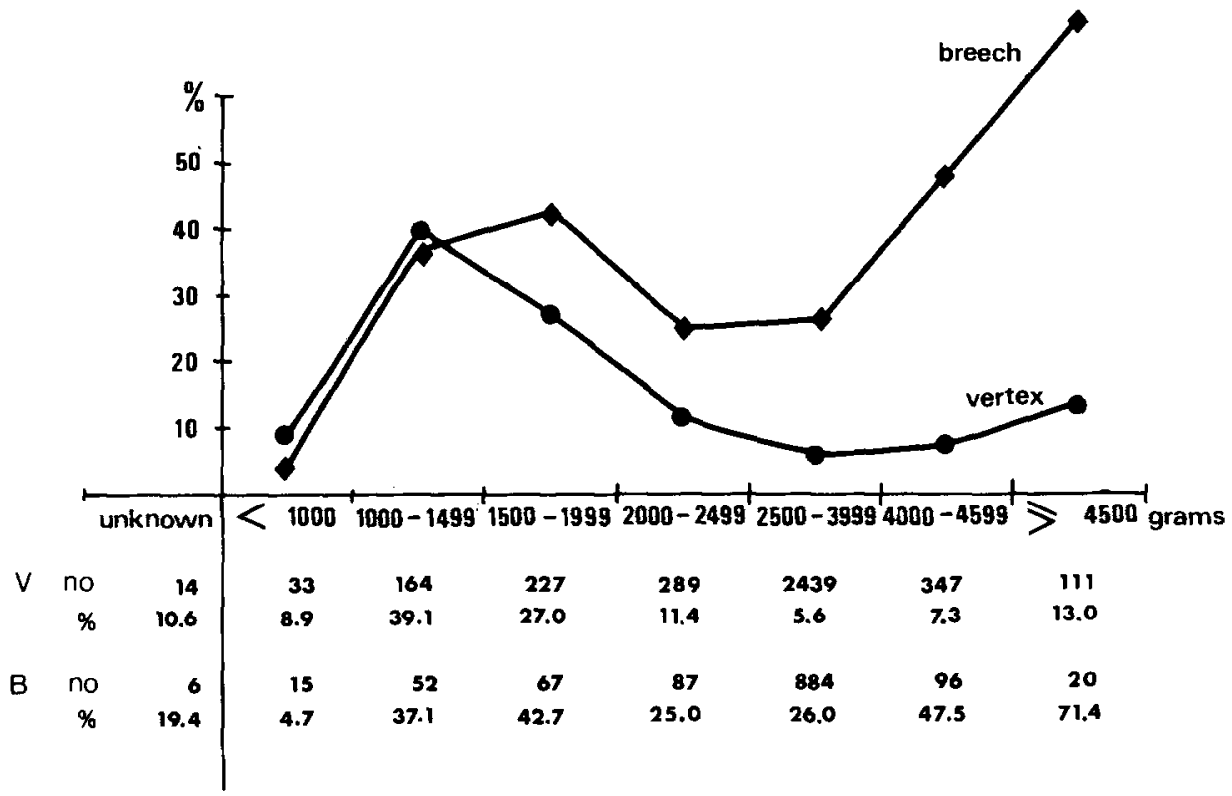

Fig. 2. The incidence of vertex (V) and breech (B) presentation according to birth weight in 57819 singleton pregnancies. 
TABLE VIII

Neonatal death after caesarean section and vaginal delivery in vertex and breech presentation

\begin{tabular}{|c|c|c|c|c|}
\hline \multirow{2}{*}{$\begin{array}{l}\text { Gestational } \\
\text { age (wk) }\end{array}$} & \multicolumn{2}{|c|}{ Caesarean section } & \multicolumn{2}{|c|}{ Vaginal delivery } \\
\hline & $\begin{array}{l}\text { Vertex } \\
\text { neonatal } \\
\text { death: } \\
\text { No. (\%) }\end{array}$ & $\begin{array}{l}\text { Breech } \\
\text { neonatal } \\
\text { death: } \\
\text { No. (䓪) }\end{array}$ & $\begin{array}{l}\text { Vertex } \\
\text { neonatal } \\
\text { death: } \\
\text { No. }(\mathscr{F}) \text { b }\end{array}$ & $\begin{array}{l}\text { Breech } \\
\text { neonatal } \\
\text { death: } \\
\text { No. (\%) b }\end{array}$ \\
\hline $28-32$ & $13(11.0)$ & $9(15.5)$ & $28(7.4)$ & $17(23.3)$ \\
\hline $33-36$ & $7(1.7)$ & $6 \quad(5.4)$ & $30(1.2)$ & 7 (3.3) \\
\hline$\geqslant 37$ & $8 \quad(0.3)$ & $10(1.0)$ & $62(0.1)$ & $17 \quad(0.7)$ \\
\hline
\end{tabular}

a Percentages calculated from the data in Table VII corrected for stillbirth.

${ }^{b}$ Percentages calculated from the combined data of Tables I, VI and VII.

Perinatal mortality in infants delivered by caesarean section was almost twice as high and significantly different $(P<0.05)$ in the breech group compared to the vertex group at any gestational age (Table VII). After both caesarean section and vaginal delivery neonatal mortality was higher in the breech group than in the vertex group $(P<0.05)$, but there was no difference in the trends of neonatal mortality with increasing gestational age.

For infants delivered at 28-32 wk, Table VIII suggests that caesarean section, when compared to vaginal delivery, may produce lower neonatal mortality in the breech group and higher neonatal mortality in the vertex group. The differences, however, are not statistically significant.

\section{Congenital malformations}

At any gestational age congenital malformations occurred more frequently in the breech group than in the vertex group $(P<0.05)$. There is a suggestive trend that with increasing gestational age the frequency of congenital malformations decreases

TABLE IX

Incidence of congenital malformations in vertex and breech presentations

Percentages are calculated from the data in Table $\mathbf{I}$.

\begin{tabular}{|c|c|c|c|c|}
\hline \multirow{3}{*}{$\begin{array}{l}\text { Gestational } \\
\text { age (wk) }\end{array}$} & \multicolumn{4}{|c|}{ Malformations } \\
\hline & \multicolumn{2}{|c|}{ Vertex presentation } & \multicolumn{2}{|c|}{ Breech presentation } \\
\hline & No. & $(\%)$ & No. & (\%) \\
\hline $16-27$ & 25 & $(8.0)$ & 21 & (8.9) \\
\hline $28-32$ & 50 & $(8.3)$ & 19 & (9.6) \\
\hline $33-36$ & 111 & (3.6) & 30 & (8.4) \\
\hline$\geqslant 37$ & 857 & (1.9) & 116 & (3.3) \\
\hline Unknown & 97 & (2.5) & 18 & (5.7) \\
\hline Total & 1140 & (2.1) & 204 & (4.4) \\
\hline
\end{tabular}


TABLE X

Perinatal death of infants with congenital malformations

Percentages are calculated from the data in Table IX.

\begin{tabular}{|c|c|c|c|c|}
\hline \multirow{3}{*}{$\begin{array}{l}\text { Gestational } \\
\text { age (wk) }\end{array}$} & \multicolumn{4}{|c|}{ Perinatal death } \\
\hline & \multicolumn{2}{|c|}{ Vertex presentation } & \multicolumn{2}{|c|}{ Breech presentation } \\
\hline & No. & $(\%)$ & $\overline{\text { No. }}$ & $(\%)$ \\
\hline $16-27$ & 24 & (96) & 21 & (100) \\
\hline $28-32$ & 32 & (64) & 17 & (89) \\
\hline $33-36$ & 31 & (28) & 18 & $(60)$ \\
\hline$\geqslant 37$ & 55 & $(6.4)$ & 24 & (20.7) \\
\hline Unknown & 23 & $(24)$ & 8 & (44) \\
\hline Total & 165 & (14.5) & 88 & (43.1) \\
\hline
\end{tabular}

TABLE XI

Perinatal death after exclusion of congenital malformations

Percentages are calculated from the combined data in Table I, III and X

\begin{tabular}{|c|c|c|c|c|}
\hline \multirow{3}{*}{$\begin{array}{l}\text { Gestational } \\
\text { age (wk) }\end{array}$} & \multicolumn{4}{|c|}{ Perinatal death } \\
\hline & \multicolumn{2}{|c|}{ Vertex presentation } & \multicolumn{2}{|c|}{ Breech presentation } \\
\hline & No. & $(\%)$ & No. & (\%) \\
\hline $16-27$ & 212 & $(73.3)$ & 196 & (91.2) \\
\hline $28-32$ & 117 & $(21.2)$ & 77 & (42.8) \\
\hline $33-36$ & 119 & $(3.9)$ & 24 & $(7.4)$ \\
\hline$\geqslant 37$ & 201 & $(0.5)$ & 27 & $(0.8)$ \\
\hline Unknown & 75 & $(2.0)$ & 35 & (11.7) \\
\hline Total & 724 & (1.4) & 359 & $(8.1)$ \\
\hline
\end{tabular}

in the vertex group; in the breech group, however, the incidence of congenital malformations decreases only from $37 \mathrm{wk}$ of gestation (Table IX).

Perinatal mortality of infants with congenital malformations decreases with increasing gestational age to a lesser extent in the breech group than in the vertex group $(P<0.01)$ and this is reflected by the overall perinatal mortality of infants with congenital malformations being much higher in the breech group than in the vertex group ( $43.1 \%$ versus $14.5 \%$, Table $\mathrm{X}$ ).

After exclusion of all infants with congenital malformations (Table XI) perinatal mortality remained higher in the breech group than in the vertex group at any gestational age $(P<0.01)$.

\section{Discussion}

In the studied 57819 computer-registered singleton pregnancies, $8 \%$ were delivered from a breech presentation (Tables I and II), while the incidence in an unselected group of singletons should be about 3.5 percent (Kauppila, 1975). The 
LVR data are derived only from hospital deliveries; breech presentation is regarded as a risk factor that requires hospital delivery and many vertex presentations are delivered in hospital only because of other risk factors. At the same time, a considerable number of home deliveries, almost exclusively of term pregnancies in vertex presentation, take place in The Netherlands and could not be included in this study. As a consequence a higher incidence of breech presentation was found than would be expected from an unselected group of singletons and the outcome of breech presentation was less unfavourable than it would have been if compared to an unselected group of vertex presentations.

The findings of Brenner et al. (1974), that, compared to vertex presentations, breech presentations are delivered at lower gestational ages and birthweights and are associated with more frequent congenital malformations which increase with gestational age, are confirmed in this study (Tables I, II, IX). Prior to 33 wk gestation there is probably little significance in the occurrence of a breech rather than a vertex presentation. After $33 \mathrm{wk}$ a vertex presentation should be the more stable.

A breech presentation may, however, arise as a result of congenital malformations that would decrease the stability of a vertex presentation, such as those associated with alterations of the amount of amniotic fluid, defects in the mobility of the lower extremities, abnormal size of the head, etc.

Part of the high perinatal mortality associated with breech presentation after 33 wk gestation (Table $\mathrm{X}$ ) may therefore be the result of these congenital malformations rather than the presentation itself. However, in this study, perinatal mortality in the breech group was higher than in the vertex group at any gestational age (Table III) and, even after exclusion of infants with congenital malformations, remained higher (Table XI), suggesting that the presentation itself is an unfavourable factor and that the method of delivery might be expected to influence fetal outcome.

However, Green et al. (1982) found only a suggestion of decreased trauma and mortality as a result of caesarean section, while Effer et al. (1983) found no differences in mortality and morbidity between infants delivered vaginally and those delivered by caesarean section when subgroups of comparable birthweight were analysed. In this study the incidences of stillbirth and neonatal mortality were higher in the breech group than in the vertex group (Tables V and VI). Because we were unable to identify in this study mortality directly attributable to delivery-related trauma we regarded neonatal mortality rather than perinatal mortality as the criterion by which fetal outcome should be judged.

If the higher neonatal mortality in breech presentation were due to the risk of vaginal delivery, neonatal mortality should be lower in those delivered by caesarean section. However, although the incidence of caesarean section was higher in the breech group than in the vertex group at any gestational age (Fig. 1), the neonatal mortality after caesarean section was higher in the breech than in the vertex group (Table VII) and there was no statistical evidence that neonatal mortality was lower after caesarean section in either group (Table VIII).

\section{Conclusions}

Perinatal mortality was always higher in the breech group than the vertex group. Congenital malformations were more frequent in infants from the breech group but, 
even after excluding them, perinatal mortality remained higher in the breech group.

Caesarean section did not seem to improve the prognosis in breech presentation.

There are probably several unrecognised factors that influence the prognosis for the breech infant and it may be that breech presentation may not be coincidental but rather a product of the quality of the infant so that the 'fittest' infants present by the vertex and the 'weakest' by the breech. If there is some truth in this supposition, it is unlikely that medical intervention based upon present knowledge can improve the outcome of infants in breech presentation to the same level as that for infants in vertex presentation. It is even questionable whether routine caesarean section for breech presentation can improve the results. In fact, 'the breech infant is more than just one who happens to be presenting buttocks first' (Brenner, 1974). Finally, computerised registration of obstetric information on a nationwide basis appears to be a useful means to provide a database for the study of obstetric phenomena.

\section{Acknowledgements}

We wish to thank Paul A.R. de Milliano for the statistical analysis and T.H. Beresford West for the work he has done.

\section{References}

Brenner, W.E., Bruce, R.D. and Hendricks, C.H. (1974): The characteristics and perils of breech presentation. Amer. J. Obstet. Gynec., 118, 700-712.

Breslow, D. (1980): Statistical methods in cancer research. The analysis of case-control studies, Vol. 1. IARC, Lyons.

Effer, S.B., Saigal, S., Rand, C., Hunter, D.J.S., Stoskopf, B., Harper, A.C., Nimrad, C. and Milner, R. (1983): Effect of delivery method on outcomes in the very low-birth weight breech infant: Is the improved survival related to cesarean section or other perinatal care maneuvres? Amer. J. Obstet. Gynec., 145, 123-128.

Eijk, E.A. van and Huisjes, H.J. (1983): Neonatal mortality and morbidity associated with preterm breech presentation. Europ. J. Obstet. Gynec. reprod. Biol., 15, 17-23.

Grimovsky, M.L. and Paul, R.H. (1982): Singleton breech presentation in labor: Experience in 1980. Amer. J. Obstet. Gynec., 143, 733-739.

Green, J.E., McLean, F., Smith, L.L. and Usher, R. (1982): Has an increased cesarean section rate for term breech delivery reduced the incidence of birth asphyxia, trauma and death? Amer. J. Obstet. Gynec., 142, 643-648.

Hemel, O.J.S. van (1977): An obstetric data-base; human factors, design and reliability. Thesis Free University Amsterdam. Vam-Voorschoten.

Jong, P.A. de and Stolte, L.A.M. (1982): The influence of spontaneous breech delivery on the integrity of the central nervous system of the newborn. Europ. J. Obstet. Gynec. reprod. Biol., 13, 23-29.

Wright, R.C. (1959): Reduction in perinatal mortality and morbidity in breech delivery through routine use of cesarean section. Obstet. and Gynec., 14, 758-763. 